Comités pro-desocupados: intervención estatal, contención social y política. Entre Ríos, 1932-1943

Rodolfo Matías Leyes

Anuario No 33 / ISSN 1853-8835 / 2020

http://anuariodehistoria.unr.edu.ar/ojs/index.php/Anuario/index

\title{
Comités pro-desocupados: intervención estatal, contención social y política. Entre Ríos, 1932- 1943
}

\section{Pro-unemployed commitees: state intervention, political and social support. Entre Rios, 1932 - 1943}

RODOLFO MATÍAS LEYES

Universidad Autónoma de Entre Ríos, Consejo Nacional de Investigaciones Científicas y Técnicas (Argentina) rodolfoleyes@yahoo.com.ar

\section{RESUMEN}

El artículo que presentamos desarrolla uno de los aspectos menos conocidos de la intervención estatal en los años treinta, los comités pro-desocupados. Pero el trabajo no se limita a la organización en cuestión, sino también a los efectos de la crisis en la ocupación y a los cambios en la conciencia de la clase dominante, que lanzó repetidos pedidos para la contención de los desocupados, de los que se temía un levantamiento revolucionario. Por lo tanto, la intervención estatal no fue solo un reclamo por más trabajo para los desempleados, sino también un mecanismo de autodefensa de la burguesía. Asimismo se estudió el uso de los comités pro-desocupados por los políticos de los partidos conservadores y radicales, quienes aprovecharon la situación de crisis ocupacional para crear un vínculo político a partir de la disputa de los recursos de los comités pro-desocupados.

Palabras clave: Desocupación- clase obrera- crisis de 1930- intervención estatalProvincia de Entre Ríos

ABSTRACT 
This arcticle expands on one of the less known aspects about state intervention during the thirties: pro-unemployed committees. Our work is not limited to this kind of organizations, but also the consecuenses of the crisis on employment and consciousness changes on dominant class, which lauched several support petitions in favor of unemployed, fearing a revolutionary uprising. Therefore, state intervention wasn't just a job demand, but also a bourgeoisie self-defence mechanism. In adition, we studied the handling of pro-unemployed committees made by conservative and radical parties politicians, whom took advantage of crisis to build political bonds by fighting for pro-unemployed committees means.

Keywords: Unemployment - Working class - 1930 Crisis - state intervention Province of Entre Ríos

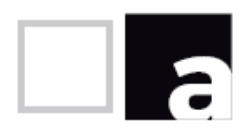

\begin{abstract}
"Es lógico suponer, frente a las circunstancias actuales, que la cantidad de desocupados irá acrecentándose poco a poco y no sería dificil que llegue a constituir en breve plazo un peligro social muy grande, por la gravedad que tal situación revestiría, estimamos debe preocupar seriamente a los Poderes Públicos."

Informes de los delegados del Banco Nación al Presidente Justo,
\end{abstract}

$1933^{1}$

\title{
Introducción
}

La crisis de la década del treinta generó cambios profundos y duraderos en la sociedad argentina. La situación así lo imponía. El capitalismo agrario argentino parecía haber llegado a su limite expansivo, la dificultad para incorporar nuevas tierras al sistema productivo y la adquisición de maquinarias más modernas habian presionado sobre los sectores chacareros más pobres y expulsado a los trabajadores

${ }_{1}^{1}$ Situación económica de la Provincia de Entre Ríos. Informe sobre la gira realizada por los Srs. Directores don Pedro Benegas y don Pedro Etchegaray y gerente de Sucursales don Manuel Gómez, los dias 19, 20 y 21 de enero de 1933, en Archivo General de la Nación. Sala VII. Fondo Agustín P. Justo. Caja No 42, documento $\mathrm{N}^{\circ} 25$, p. 6 .

\section{anuario.}


de los empleos. La desocupación de los treinta, que se hacía sentir desde años antes (O’ Connell, 1984; Leyes, 2018.), dejó a miles de obreros y un número incuantificado de chacareros proletarizados a la vera de los caminos, literalmente. Por este motivo es que podemos señalar que la desocupación es una de las manifestaciones fenoménicas más importantes de la crisis y palanca de los cambios.

Pero no solo el aumento de la desocupación fue una novedad persistente en la realidad argentina. La década del treinta empujó al estado a tomar nuevas funciones. Si la desocupación fue la manifestación de los límites del capitalismo expansivo, ello no significó que el estado mirara impávido la crisis del sistema social, ni tampoco continuó con la política de dejar hacer al mercado, con la esperanza liberal de que las cosas se resuelvan por una mano invisible, que en el peor de los casos, se apoyaba en el puño de hierro de la represión. No, el estado se convirtió en un actor central de la realidad.

Entre las múltiples misiones asumidas por el estado en el ámbito provincial, el presente artículo tiene por objetivo mostrar el desarrollo de un tipo de organización particular, los llamados "Comités pro-desocupados". Verdad es que no fue la única estrategia que buscó contener la desocupación, pero sí fue la más extendida territorialmente y significó una novedad en el ámbito de la provincia de Entre Ríos. En efecto, a pesar de intentar la creación de ollas populares o gestionar ante el estado nacional por fondos para la obra pública, los comités pro-desocupados se destacaron por su persistencia hasta el golpe de junio de 1943. Asimismo contaron con financiación provincial y el aporte de diversos sectores, hecho que determinó un funcionamiento complejo y fundamentalmente, forjaron nuevos vínculos entre los desocupados y los encargados de la administración de los recursos públicos. Es decir, los "comités pro-desocupados" generaron un nuevo tipo de relaciones entre diversos actores de la sociedad.

Ahora bien, la contención de la desocupación no era motivada por razones humanitarias, sino por la subsistencia del propio capitalismo. La burguesía entendia perfectamente que la masa de desocupados era potencialmente un peligro social. En primer lugar porque esa masa de obreros en paro buscaría obtener el pan de cualquier modo, y esto implicaba, la mayoría de las veces, atacar la propiedad privada, por lo tanto la burguesía sería la más afectada. Pero también existe otro motivo que preocupó. La clase dominante deducía que esa masa de desocupados era potencialmente revolucionaria. Es decir, había comprensión de que los desocupados serían permeables a la propaganda revolucionaria, en particular comunista, y con ellos, los ataques a la propiedad no serían esporádicos, sino definitivos. 


\section{Comités pro-desocupados: intervención estatal, contención social y politica. Entre Rios, 1932-1943}

La historiografia ha mostrado estas nuevas formas de intervención en una variedad de aspectos de la vida social ${ }^{2}$, sin embargo, aún restan varias temáticas de importancia y en particular las funciones desarrolladas por los estados provinciales. Los estudios sobre la relación entre el estado y la clase obrera centran su atención, especialmente, en la mediación estatal de la conflictividad o en los intentos de organizar a los desocupados para la lucha revolucionaria. En ninguno de los dos casos aparece el estado ocupando el lugar de gran capitalista que genera empleo y busca contener a los desocupados. Hecho llamativo, dado que es una función de indudable continuidad en la realidad argentina.

Los primeros estudios específicos sobre la relación entre el estado y la clase obrera fueron desprendimientos de los debates sobre los orígenes del peronismo. Aquella discusión entre "continuistas" y "rupturistas", ubicó al estado en un lugar destacado ${ }^{3}$. Dentro de la línea continuista, los trabajos de Ricardo Gaudio y Jorge Pilone (1983 y 1984) mostraron el cambio que se sucedió en el ámbito de los gobiernos conservadores frente a la conflictividad obrera durante el último lustro de la década del treinta. La dependencia que encarnó el cambio fue el Departamento Nacional del Trabajo. En la misma línea, pero con una visión nacional de la intervención estatal y la conflictividad, se encuentra el trabajo de Korzeniewicz (1993) quién además incorporó las luchas del proletariado rural y la actividad de los departamentos provinciales del trabajo. Continuando esa linea de estudios, Juan Suriano y Mirta Lobato compilaron estudios sobre el estado y el mundo del trabajo, de los cuales, varios se refirieron a las funciones en la contención social de los departamentos provinciales de trabajo (Garzón Rogé; Ullivarri; Ortiz Bergia; Piazzesi, 2014), a los que deberíamos agregar el trabajo de Leyes y Sartelli sobre el departamento provincial del trabajo de Entre Ríos, único estudio centrado en la provincia mencionada y que muestra la voluntad interventora como co-relato de la represión de mediados de 1930 contra los anarquistas de Diamante.

Los trabajos reseñados estudian como el estado encaró la cuestión obrera pero de los trabajadores ocupados. Más específicamente, de aquellos trabajadores que con empleo se embarcaban, junto con a sus sindicatos, en la lucha por mejoras económicas. ¿Pero qué hay de los desocupados? Omitiendo los pocos trabajos que tratan la desocupación e intentaron ofrecer explicaciones al fenómeno en los treinta (Panettieri, 1996; 1997. Para el ámbito entrerriano: Leyes, 2016; 2018), son los estudiosos del comunismo argentino quienes indicaron la construcción de comités de desocupados para realizar reclamos. Uno de los principales trabajos en esta

\footnotetext{
${ }^{22}$ La bibliografia sobre intervención estatal en los '30 es prolífica y está en permanente actualización, sólo indicaremos algunas obras de referencia a este trabajo: Intervención en la economía rural: Barsky y Gelman, 2005, cap. VIII y la compilación de Balsa, 2012. Sobre industria: Schvarzer, 2000, cap. V y VI.

${ }^{3} \mathrm{E} 1$ núcleo de los debates era la continuidad entre la política previa a 1943 o la ruptura. La base de esta discusión era demostrar, por parte de los continuistas, que muchas de las políticas de Perón no era novedosas. El debate se puede reconstruir desde: Germani, 1962 y Murmis y Portantiero, 2006. Finalmente la compilación: Mora y Araujo y Llorente, 1980.
} 
línea es el de Nicolás Iñigo Carrera (2016: cap. 6). Según su opinión los desocupados serían una de las bases sociales para la construcción de la "otra estrategia", es decir, la estrategia revolucionaria dentro del movimiento obrero argentino. Por otra parte el trabajo de Benclowicz (2016) analiza la intervención comunista en la organización de los desempleados, e indica el temor de la burguesía a la situación de los parados, así como los logros de los militantes del Partido Comunista en la organización de los desocupados. En resumen, la historiografia se ha ocupado de los elementos de nuestro estudio: la intervención estatal por un lado, la organización de los desocupados por el otro, pero no los ha tratado juntos. Por nuestra parte nos inclinamos a estudiar el funcionamiento de las comisiones pro-desocupados como un puente que tendió la clase dominante para contener a los desocupados.

Nuestra hipótesis de trabajo es que el estado, como organización superestructural y garante de la reproducción del régimen capitalista tomó, en la medida de sus capacidades la tarea de contención bajo nuevos cánones y ocupó a los desempleados. Acción que era reclamada por diversos actores, de diferentes regiones de la provincia, en un llamativo consenso interventor. Pero como el estado también sufría la crisis, especialmente en sus finanzas, buscó conseguir recursos por aportes privados. Esta situación permitió que los políticos burgueses intervinieran de modo "clientelar". Recién hacia los años cuarenta, y casualmente cerca de periodos eleccionarios, se consiguieron partidas presupuestarias específicas. Por lo tanto el artículo muestra las transformaciones del estado, pero también del quehacer político en una provincia signada por la crisis económica.

Esta particular configuración de un estado quebrado y el uso proselitista que los partidos patronales desarrollaron nos permiten reconocer los mecanismos clientelares sobre los que se construyeron las alianzas politicas que consolidaron el poder de los radicales frente a la clase trabajadora. En este sentido, la política de contención de los desocupados, complementaron las relaciones que los radicales habian generado con los obreros ocupados a partir de una alianza tácita con el gremialismo sindicalista (Leyes, en prensa), y editaban una nueva práctica que habilitaba la representación de los intereses obreros dentro del aparato estatal que los radicales dirigian.

La reconstrucción histórica se realizó con diferentes tipos de fuentes que incluyeron diarios y periódicos de diversas ciudades entrerrianas, así como documentos estatales del Ministerio del Interior, pertenecientes al acervo documental del Archivo General de la Nación y material estadístico e informes estatales producidos por el estado nacional y provincial. 


\section{Comités pro-desocupados: intervención estatal, contención social}

y politica. Entre Rios, 1932-1943

\section{1- Particularidades entrerrianas}

La provincia de Entre Ríos posee una serie de particularidades que debemos mencionar a fin de dar cuenta de su situación estructural, sindical y política. Elementos necesarios para comprender el contexto en el que se generó la aparición de las comisiones pro-desocupados.

Lo primero que se debe indicar es que Entre Ríos pertenece a las provincias llamadas pampeanas, es decir, con un fuerte peso de las actividades agrícolas cerealeras, acompañadas de una no menor participación de las actividades pecuarias (Biaziso, 2015).

La producción cerealera se desarrollaban en las colonias agrícolas y crecientemente, desde mediados de los años veinte, en estancias. Aunque la preeminencia productiva de la pequeña propiedad chacarera se destacaba, con una particularidad que era la gran cantidad de propietarios minifundistas. Nemirovsky (1933: 94-95) indicó que entre 1925-1926, la provincia de Entre Ríos contaba con un 45,89\% de propietarios y 54,11 de arrendatarios. Comparativamente, Santa $\mathrm{Fe}$, el otro gran centro colonizador de la pampa húmeda, poseía 36,94\% de propietarios y 63,06\% de arrendatarios. Con respecto a la propiedad de la tierra, el Censo Nacional Agropecuario de 1947 mostró que de 36.969 propiedades existentes en la provincia, 40,9\% (2.939.747 hectáreas) eran explotadas por sus propietarios. (Ministerio de Asuntos técnicos del Estado, 1952: 10-11)

El problema central del agro-entrerriano no era la propiedad de la tierra, sino la superficie disponible. En 1937, sobre 28.409 propiedades, 17.947 eran superficies de entre 1 a 100 hectáreas. Inclusive, el número mayoritario de este sub-grupo (11.785 propiedades) era de 1 a 50 hectáreas (Ministerio de Agricultura, 1940). Con 25 a 50 hectáreas en promedio, poco era lo que podian hacer los propietarios. Ricardo Ortiz señaló con relación a la crisis del treinta: "Entre Ríos había sido mucho más castigado, porque la extensión media de sus chacras quedaba debajo del mínimo vital aun en años de buenos precios" (Ortiz, 1964: 118-119, T. II).

Mientras tanto, en las grandes superficies rurales, la principal actividad ganadera era la cría y el engorde de ganado vacuno para el abasto de las industrias procesadoras de carne y el consumo interno. Como valor de referencia, la media anual de vacunos faenados entre 1934-1943 era 478.054 cabezas de vacunos. También en promedio, el $51,4 \%$ del producto resultante era consumido en el país, mientras el restante $48,5 \%$ era exportado. El cambio más importante dentro de las actividades ganaderas la sufrió el lanar, cuando, luego de alcanzar su máximo histórico en 1908 con cerca de siete millones, paso a estabilizarse en cerca de dos millones y medio (República Argentina, 1909: 57, Vol. I). Es decir, el 30\% de lo que fue en su mejor momento.

\section{anuario.}


Estas dos ramas productivas, la agricultura y la ganadería, concentraban gran cantidad de mano de obra, dividida en tareas que iban desde la simple roturación de la tierra, la cosecha y el cuidado del ganado hasta las, mucho más importantes, trilla, estiba y esquila, era mediado por tiempos muertos sin trabajo, cuando el proletariado rural esperaba desocupado el comienzo de las nuevas actividades anuales.

Esta matriz netamente agrícola, dependiente de los altibajos de los precios de los productos de exportación y sus cosechas perdidas por las lluvias o por las sequías, generó una miriada de pequeños pueblos y ciudades, ninguna más importante que otra y con una gran dispersión geográfica por el territorio provincial, hecho único en la región pampeana. Hacia 1914, Entre Ríos contaba con solo 17 poblados de más de 2.000 habitantes en una población de más de 425 mil personas, de las cuales el 61,3\% de población rural. (Tercer Censo Nacional, 1917: 469-475, T. IV. Tercer Censo Nacional, 1916: 108, T. I. Tercer Censo Nacional, 1916: 249, T. II) Para 1947, con un crecimiento poblacional del $85 \%$ con respecto al Censo Nacional de 1914, las ciudades de más de 2.000 habitantes alcanzaban los 30 poblados y apenas el $50,1 \%$ de su población era urbana. (IV Censo General de la Nación, 1949: 227, 232; 662-670)

En estas ciudades se desarrollaba el procesamiento de las materias primas locales. Caso paradigmático son los frigoríficos y fábricas de extractos de carne. Pero también son de destacar las actividades del abasto de los pueblos, aquellas actividades que toda planta urbana poseía de acuerdo a su tamaño demográfico, panaderias, herrerias, imprentas, zapaterias. Todas estas actividades industrias o manufactureras estaban atravesadas por un incremento de la mecánica, hecho que expulsaba obreros de modo creciente. (Leyes, 2018)

Sobre esta base material se fue conformando un mercado de fuerza de trabajo acostumbrada a la ocupación intensiva estacional y a meses de desocupación flotante. Por lo tanto, se formó una clase obrera que tuvo fuertes dificultades para organizarse, aunque esto no impidió la constitución de sindicatos. En 1932 la clase obrera entrerriana logró un viejo sueño que era la creación de un organismo que centralice, a escala provincial, a los gremios. Este organismo, la Unión Obrera de la Provincia de Entre Ríos, se constituyó en la ciudad de Concepción del Uruguay con la participación de una treintena de gremios, en su mayoría vinculados a la estiba y el acarreo de cereal, y a partir de la confluencia de dos corrientes ideológicas del movimiento obrero, los sindicalistas, asentados en Concepción del Uruguay y los anarquistas de Diamante. Este paso adelante en la organización permitió a la clase trabajadora organizada, a pesar de su debilidad estructural y la creciente desocupación, realizar un ciclo de luchas gremiales que vivió su punto más alto de conflictos en el año 1935 con treinta y siete huelgas. Sin embargo, el ascenso se vería interrumpido por una serie de desavenencias entre los dos grupos ideológicos

\section{anuario.}




\section{Comités pro-desocupados: intervención estatal, contención social y politica. Entre Rios, 1932-1943}

que terminó con la expulsión de los anarquistas y la posterior constitución de otra central provincial, la Federación Obrera Comarcal Entrerriana dirigida por los ácratas con sede en Diamante (Kabat y Leyes, 2018).

Así fue que a mediados de los treinta, cuando la organización llegaba a su punto más alto se produjo la ruptura entre sindicalistas y anarquistas. Pero la clase dominante tomó nota del ascenso de la conflictividad y creó una carta orgánica para el Departamento Provincial del Trabajo, hecho que le permitió una fuerte intervención en los enfrentamientos entre el capital y el trabajo. (Leyes y Sartelli, 2019: 12) Fueron justamente los años 1935 -el de mayor conflictividad- y 1937, los de mayores intervenciones. Este segundo año, 1937 marca el fin de una coyuntura de la vida de la clase obrera entrerriana cuando los anarquistas lanzan una serie de huelgas de estibadores que serán un fracaso y terminarán con una fuerte represión, clausura de los sindicatos y la destrucción de la experiencia libertaria (Arnaiz, 1991).

Si bien este cambio de coyuntura muestra como el estado, a fin de cuentas, aplica la violencia cuando hay convulsiones sociales, la intervención mediadora en las luchas obreras generó por otro lado un fortalecimiento de los sindicatos, que a partir de allí eran reconocidos -siempre que se encuadraran en parámetros aceptables para el estado- y apuntalaban estructuras gremiales débiles estructuralmente hablando. En este sentido, la clase obrera entrerriana a mediados de los treinta, era integrada crecientemente, del mismo modo que sucedia en otras regiones del país (Tcach, 1991, Béjar, 2005, Ulivarri, 2009, Mastrángelo, 2011, Prol, 2012, Garzón Rogé; Ullivarri; Ortiz Bergia; Piazzesi, 2014).

Esta capacidad adaptativa del estado tiene por origen la politica de los radicales, quienes gobernaron Entre Ríos ininterrumpidamente desde 1915 a 1943. Esta disposición para realizar cambios fue una de las estrategias politicas que les permitió saltar la intervención de la provincia en 1930 e ir haciendo lo que fuera necesario para continuar en el poder. En un contexto de normalidad institucional, dónde las elecciones dirimen la continuidad administrativa, los votos son centrales y se hace necesaria la creación de lazos con la clase obrera, cualesquiera sea su condición ocupacional. Es decir, comienzan a cobrar mayor importancia los obreros como votantes, no solo como potenciales creadores de desmanes. Así se fue tejiendo un vínculo creciente con los trabajadores a los que convocaron como sus representados. (Leyes, en prensa)

En conclusión, en una provincia de marcada identidad agraria, con un peso creciente del movimiento obrero organizado, hacía falta un organismo del estado que responda a los trabajadores sin trabajo. Esa fue la función de las comisiones pro-desocupados. 


\section{2- La desocupación de los años treinta en Entre Ríos}

La desocupación es un hecho común en el capitalismo. Factores que pueden explicar el fenómeno del desempleo en nuestro caso de estudio son, además del papel central que le cabe a la mecanización, la concentración regional de la industria en el eje Buenos Aires-Rosario, la decadencia de algunas ramas productivas en Entre Ríos, sin olvidar la retracción comercial de los treinta y las cosechas perdidas en diferentes años. En 1931, El Litoral informó que el Ministerio de Gobierno de la provincia se había dirigido a los jefes de policía para conocer la situación de los desocupados. El medio enumeraba algunas de sus causales:

“...la paralización de la fábrica de conservas de carne de la Compañia Saladeril, que el año anterior, a estas horas, daba ocupación remuneradora a cerca de 1000 personas, entre hombres, mujeres y menores (...) En segundo lugar se observa que la edificación urbana ha disminuido considerablemente, reduciendo el trabajo de los hornos [de ladrillos], del transporte, de la albañilería y de todos los ramos afines o vinculados directa e indirectamente a esa actividad (...) en los distritos rurales, los resultados conocidos del año agricola; en la ciudad, además de las causas ya expresadas, la reducción de personal de las obras del F. C. del Estado; el retorno de muchos trabajadores cesantes de la fábrica de Liebig, aquí radicados; la afluencia de elementos de distintas localidades, en los cuales Concordia ejerce la atracción de su importancia en la zona, haciéndoles alentar la esperanza de que en su seno han de encontrar los medios de ganarse el pan de cada día. Podrian citarse sin duda otras causas entre ellas la merma de las actividades ferroviarias y demás transportes."4

El fenómeno de la desocupación escondía el funcionamiento del sistema capitalista que, basado en la competencia, genera enfrentamientos entre los capitalistas por el mercado recurriendo al aumento de la explotación de los obreros y a la incorporación de maquinarias para ser más productivos. Efecto de esta lucha será la quiebra de los capitalistas menos productivos y la desocupación de los obreros. Estos ciclos de competencia expulsan mano de obra permanentemente, pero será en momentos de crisis, cuando la tasa de ganancia está en su punto más bajo, que estos fenómenos se extienden y la expulsión se generaliza. (Shaikh, 2006) La crisis que comenzó durante los últimos años de la década del veinte fue un claro ejemplo de este proceso, dónde la desocupación se potenció.

El primer censo de desocupación de la nación, realizado en 1932, fue elocuente sobre la situación entrerriana. Se calculó que eran 20.230 los trabajadores desocupados, pero como veremos no fue una excepción. En 1937, el director del Departamento Provincial del Trabajo envió una nota a la Junta Nacional para Combatir la Desocupación con un cálculo aproximado de veinte mil obreros sin

4Periódico El Litoral, Concordia, 14/08/1931. 


\section{Comités pro-desocupados: intervención estatal, contención social y politica. Entre Rios, 1932-1943}

trabajo. En 1940, la desocupación seguía a la orden del día, se informó que a pesar de las medidas tomadas por el Estado -obra pública especialmente- aún se mantenían desocupados unos 10.000 obreros. Un último cálculo, que si bien excede el periodo del artículo permite reconocer el carácter permanente de la desocupación: en 1945 la Dirección de Estadística Social de la Revolución del 4 de junio solicitó a los interventores de Entre Ríos datos referentes a los desocupados en 1945, estos informaron que había por lo menos 15.800 desocupados en la provincia y que en las ciudades era dónde más se sentía la falta de trabajo ${ }^{5}$. En diversas comunicaciones las autoridades públicas reconocían un promedio de entre diez mil a veinte mil desocupados permanentes en el territorio provincial, las entidades gremiales ponían en duda la veracidad de los números y los métodos de medición que no eran técnicamente correctos, y argumentaban que podía ser hasta cuatro veces ese número (Leyes, 2018: 65). Hay que agregar que si el número no era mayor se debía a la emigración de los desocupados (Leyes, 2016).

La transformación del aparato productivo sumada a los factores coyunturales, comerciales y climatológicos, produjeron la formación temprana de la sobrepoblación obrera (Kabat, 2009: 109-128) en la provincia de Entre Ríos. Por este motivo es que se puede reconocer la desocupación más allá de la coyuntura de crisis comercial. Se trató de la crisis de Entre Ríos como espacio de acumulación de capitales bajo las fuerzas productivas de la época.

\section{3- Desocupados y orden social}

Si bien la desocupación sirve al capitalismo por su función reguladora del precio de la fuerza de trabajo y para disciplinar a los obreros, una gran cantidad de desocupados se puede volver un problema. Por regla, los conflictos que se suscitaban con los desocupados eran reprimidos por las fuerzas policiales. Por ejemplo, en 1933, se daba la siguiente noticia:

\footnotetext{
"Esperanzas esfumadas. Un diario de Colón hace resaltar la nota de honda tristeza que pone en el escenario lugareño, el espectáculo de los obreros que habiendo ido de los distintos puntos de la provincia a Fábrica Colón [Fábrica Liebig] en busca de trabajo, no lo han encontrado. Esa pobre gente que esperanzada en hallar ocupación dejaron sus hogares, se resistian a volver, tal vez ante la visión desesperante de tornar a sus casas, vacias las manos, sin un mendrugo de para sus hijos y con la ingrata nueva de haber sido inútil toda tentativa de poder ganarlo. La policía ha tenido que proceder a disolverlos, y sólo así cada uno ha tomado su camino, triste, desilusionado, mascullando en sus labios en vez de saborear el trozo de pan buscada, una amarga protesta..."6
}

\footnotetext{
5Figuerola, 1933: 10; 14. Junta para combatir la desocupación, 1937: 97. Departamento Nacional del Trabajo, 1940: 38. República Argentina, 1946: 86.
}

6Periódico El Censor, Gualeguaychú, 03/02/1933. 
También en 1933, un diario de Villaguay informó con el título "Invasión de desocupados" la siguiente noticia:

"Esta mañana, poco después de las diez horas, invadió la ciudad un contingente de desocupados a caballo. Lo componian veinte y dos personas. Veinte y dos hombres de trabajo, salidos de los campos, hambrientos y cubiertos de harapos, que al verse sin ocupación y ante la perspectiva de delinquir para seguir viviendo, se han decidido exigir de los politicos de la ciudad el cumplimiento de las promesas (...) Los desocupados se congregaron frente al domicilio de un conocido politico oficialista. (...) Con acento firme revelador de que están dispuestos a todo, le dijeron que son más de doscientos los que se encuentran decididos a exigir que se les de trabajo en las obras de terraplenamiento de los caminos de acceso al puente 'La Laguna'. En vista de que los desocupados se disponian a continuar por mucho tiempo frente a su escritorio en actitud amenazante, el politico solicitó la intervención de la policía para que de forma amistosa los hiciera desistir de sus propósitos nada tranquilizadores." 7

La noticia concluye dando cuanta que el comisario local entregó un peso a cada uno de los desocupados y solicitó un plazo de veinticuatro horas para darles una solución. Efectivamente, frente a una masa de personas sin medios de producción, desprovistos de contratación, era altamente probable que atacar la propiedad privada para hacerse del pan fuera una opción. En 1932, El Debate de Gualeguay comentaba como el abigeato había aumentado al ritmo de la desocupación: "En esa zona de Alcaráz [departamento La Paz] hay mil doscientas personas desocupadas, que imposibilitadas de ganarse el sustento diario roban para subvenir a las exigencias de la vida." Se informaba que la policía había atrapado a una banda en esa zona rural que tenía dos mil cueros de oveja escondidos ${ }^{8}$. En Gualeguay, se advertía que los desocupados se dedicaban a robar los alambres y postes de los alambrados para subsistir ${ }^{9}$. También había crecido el número de grupos de desocupados que se dedicaban a pedir en los caminos a la gente que pasaba. En 1933, se noticiaba que en Diamante y Nogoyá, grupos de obreros sin trabajo "con sendos cuchillos", se escondian a la vera de los caminos rurales a la espera que los transeúntes les dieran algo. El diario que nos sirvió de fuente reclamaba por su represión porque, según entendia: "Ha quedado demostrado que en Paraná, los desocupados son en su mayoría extranjeros de malos antecedentes, ladrones, jugadores y con dinero. Son además comunistas", remataba ${ }^{10}$. Ese mismo año se informó que se había echado de la provincia a 300 desocupados que habitaban los galpones de la Sociedad Rural de Paraná. Según la policía se trataba de desocupados y comunistas, por lo tanto, potenciales creadores de desmanes ${ }^{11}$.

${ }^{7}$ Periódico El Pueblo, Villaguay, 13/02/1933.

8Periódico El Debate, Gualeguay, 30/01/1932.

${ }^{9}$ La Juventud, 26/03/1942.

${ }^{10}$ El Debate, 31/01/1933. El Debate, 08/04/1933.

${ }^{11}$ El Debate, 02/02/1933. 
Decía un diario conservador con el titular "Hay desocupados que se les debe vigilar":

"La policía de Paraná observaba los reiterados robos de aves de corral y otros efectos que se producian en locales cercano al que ocupaban los desocupados. La policía fue en investigación al punto donde se alojaban los desocupados. Conducidos a la policía a ninguno le faltaba sus buenos pesos en el bolsillo y a no pocos, pésimos antecedentes registrados en las policias de otras provincias (...) Unos fueron alojados en la policía y otros debieron oblar la multa correspondiente consiguiendo su libertad."12

Días más tarde, el mismo medio, reproduciendo la noticia del diario porteño La Prensa, afirmaba:

"...los [desocupados] de hoy piden limosna y la complementan con el robo. Casi todos son extranjeros y en una gran proporción polacos, comprobación que entristece y apena pues evidencia que Polonia después de sus grandes esfuerzos para conquistar su libertad, envía los indeseables, elementos maleantes y es preciso reconocer que esa inmigración procede de cualquier país, plantea un interrogante, de si ha llegado el momento de fiscalizar bien la entrada de extranjeros a nuestro país y que ha llegado el momento, de devolver a sus paises de origen a los ladrones, jugadores, comunistas e indeseables de cualquier especie y si los paises de donde proceden los rechazan, siempre les abrirán los brazos sus camaradas del soviet ruso."13

La idea de los indeseables para caracterizar a los desocupados es permanente, así como la intención de relacionar a los desocupados con los comunistas. Fueron situaciones de este tipo las que impulsaron un consenso respecto a la necesidad de intervención estatal.

\section{4- Consenso interventor y la contención preventiva}

El presente apartado muestra el consenso entre los diferentes grupos sociales en torno a la necesidad de la intervención estatal. El interés en describir este "acuerdo" es exponer un cambio de conciencia de grandes alcances en la vida política. Como oportunamente fue señalado por Ricardo Sidicaro (1995), fue la convergencia de diversos actores asociados a la clase dominante los que impulsaron los cambios, y no, como se puede suponer, obra de nuevos actores que lograban concretar sus programas políticos. Este elemento señalado por Sidicaro nos permite entender el alcance y los límites de la acción que buscaba adaptarse a la nueva situación de crisis, sin cambiar de fondo el modelo de acumulación capitalista. Por ejemplo, en 1937, el presidente del Departamento Provincial del Trabajo infería que la única

\footnotetext{
${ }^{12}$ El Censor, 26/01/1933.

${ }^{13} \mathrm{El} \mathrm{Censor,} \mathrm{30/01/1933.}$
} 
forma de evitar la desocupación y las emigraciones era intensificar las actividades agrícolas, por ello el gobierno había comenzado un plan de colonización estatal e industrialización de los productos agrícolas (Junta Nacional para Combatir la Desocupación, 1937: 98-99). Otro caso similar aparece en los comentarios de los miembros del Departamento Provincial del Trabajo cuando, desde las hojas de su boletín mensual, afirmaban que la desocupación estacional debía ser superada con una mejor organización del trabajo y planes de obra pública (Entre Ríos, 1940),

Las referencias a los desocupados aparecen también como un dato aleatorio en los discursos inaugurales de las actividades de las cámaras legislativas, pero uno de ellos, correspondiente al año 1940 tiene un particular valor porque se refieren a las comisiones pro-desocupados. En efecto, Enrique Mihura, gobernador de aquel momento, dio cuenta de los desembolsos de dinero para el financiamiento y afirmó que:

\begin{abstract}
"Aún cuando la premura de las circunstancias obligó a improvisar los planes de trabajo, la partida votada al efecto fue aprovechada útilmente (...) Las comisiones se desempeñaron con toda eficacia, contribuyendo a ello las municipalidad, que cooperaron facilitando elementos de trabajo y materiales de que disponian. El resultado de esta experiencia ha demostrado la conveniencia de incluir en la ley de presupuesto una partida razonable para combatir la desocupación estacional" (Mihura, 1940: 8)
\end{abstract}

La percepción del mandatario de que la desocupación era un fenómeno estacional vino a ser desmentido por los propios censos realizados y reproducidos en este trabajo, pero no deja de ser interesante para el estudioso que el gobernador recomendaba financiar las comisiones por su buen funcionamiento. Es decir, era un fenómeno "estacional" pero había que financiar su funcionamiento.

Varias voces se unieron a ellos con sus respectivas propuestas, aunque destacamos que en la mayoría de ellos aparecen tres elementos asociados: la desocupación, la presión social/peligro al orden y la necesidad de la intervención estatal. También hemos notado que, si bien el problema es mencionado con anterioridad, es a partir de 1930 cuando hay una mayor atención y emerge el consenso público sobre la necesidad de la intervención estatal.

Por ejemplo, el periódico conservador El Entre Ríos, publicó entre junio y diciembre de 1931 una gran cantidad de notas referentes a la intervención estatal de cara al problema de la desocupación ${ }^{14}$. Una de ellas plantea lo siguiente:

14Ver: Periódico El Entre Ríos, Colón, desde junio a diciembre de 1931. Ver: El Entre Ríos, 27/06/1931; El Entre Ríos, 30/07/1931; El Entre Rios, 11/08/1931; El Entre Ríos, 27/08/1931; El Entre Ríos, 08/09/1931; El Entre Ríos, 12/09/1931; El Entre Rios, 22/12/1931. 


\title{
Comités pro-desocupados: intervención estatal, contención social
} y politica. Entre Rios, 1932-1943

\begin{abstract}
"En casi todos los pueblos donde se ha prestado alguna atención a la desocupación, se ha encarado el problema con medidas elementales: ollas populares, suministros, reparto de viveres. Actitudes generosas, pero insuficientes, y que más bien sirven para dilatar el mal, en lugar de contenerlo" continuaba: "En Alemania, en cambio, se ha optado, muy cuerdamente, por un recurso que ha de resultar de excepcional eficacia: hacer que los propios desocupados se procuren sustento" -¿Y cómo lo harian?: “...el gobierno alemán ha resuelto radicar a 100.000 desocupados, con sus respectivas familias, en pequeños lotes de media hectárea cada uno, ubicados en tierras fiscales..." agregando que esto era un beneficio: "...afincando siquiera a medias a esos menesterosos y desplazarlos de la congestionada atmósferas de las grandes ciudades. Doble beneficio, del que se deriva otro no menor; alejar a tantos desesperados de la válvula peligrosa de las ideas subversivas, a las que suelen aferrarse como último recurso."15
\end{abstract}

En otra nota, pero en este caso del periódico Antorcha del Centro de estudiantes de Filosofia de Gualeguaychú, se pedía en octubre de 1931, que los patrones no debian cerrar sus fábricas por la falta de producción, dado que los trabajadores habían aguantado con mucho "estoicismo" y que empujados por la necesidad podían dar "paso a la jauría, que se esconde en cada oprimido"16. Otro caso era el diario de Paraná, La Provincia, un medio que normalmente se presentaba moderado a las controversias, señalaba:

"Resulta penoso el cuadro -capaz de conmover al corazón más duro- presenciar en los barrios suburbanos, principalmente en las adyacencias de los caminos de acceso a la ciudad, a la estación del ferrocarril, puerto y calles apartadas, los campamentos que han levantado verdaderos batallones de gente desocupada"

El autor anónimo de la nota reclama al Estado por su acción, asociado a vecinos pudientes para crear trabajo rotativo así: “...buena parte de esos parias hallaría el consuelo de saber que su odisea será interrumpida mediante la rotación de personal, que podría convenirse entre autoridades y vecinos, para evitar desastres mayores con un sistema de turno en los trabajos de emergencias." 17 La nota es interesante en cuanto expresa los elementos que mencionamos anteriormente, con el agregado de la propuesta de qué hacer antes que las cosas se desmadren cuando estos "hambrientos, sin patria y sin pan" se junten.

Cuando comenzó a circular la noticia de que se haría el primer censo de desocupados en 1932, El Debate dijo que la desocupación era el tema más importante que debía enfrentar el estado. Aunque su advertencia estaba dirigida por el temor a la evolución ideológica de los desocupados: "La desocupación es un magnífico veneno de ideas desorbitantes, anárquicas, como que el hambre con sus

${ }^{15}$ El Entre Rios, 01/10/1931.

16Periódico Antorcha, Gualeguaychú, Órgano Centro de Estudiantes de Filosofia, 08/10/1931.

17Periódico La Provincia, Paraná, 25/11/1931. 
sombrias ulterioridades, dispone la mente y el brazo hacia especulaciones pesimistas y arbitrarias. Así cuaja el comunismo y sus sectas congéneres."18

Los años pasaban, y a la par de la persistencia de la desocupación, los llamados a la ocupación por parte del estado se mantenían. Un periódico vinculado al radicalismo de Concepción del Uruguay, en una larga editorial sobre la desocupación señaló:

"El próximo invierno será duro para los trabajadores rurales y jornaleros urbanos. La pérdida de la cosecha con la secuela de factores negativos que engendra y la disminución de las obras públicas y edificación incidirá sobre las actividades generales, repercutiendo asi mismo en las finanzas provinciales. Ese paro forzoso debe evitarse a todo evento. La caida de brazos, como lo hemos sostenido, y lo seguiremos machacando hasta formar conciencia en los hombres de gobierno, no ejerce una influencia moral malsana sobre el espiritu de las masas proletarias, obligándolas a la holganza, viviendo de la caridad pública o de los subsidios del estado. Partiendo de la base que el ciudadano tiene el derecho al trabajo, los poderes públicos, especialmente la Nación, poseedora de grandes reservas y posibilidades financieras debe arbitrar los medios más eficaces y urgentes para plantear la construcción de obras imprescindibles y productivas..."

La nota, que interviene en la disputa provincia/nación por los recursos, continúa con una crítica al subsidio por considerarlo una dádiva corruptora, pero necesaria para activar el consumo obrero, motor del comercio, el transporte, la industria y las actividades bancarias. Sentenciaba: "nuestro país descansa sobre el músculo de sus obreros. Verdaderos creadores de riquezas nacional..."19 Por su parte, en septiembre de 1940, El Entre Ríos de Colón, vinculado al Partido Demócrata Nacional, publicó una nota titulada "La desocupación entre nosotros. Deber de la Nación y la Provincia":

"El mal de la desocupación que aqueja al país entero ha adquirido entre nosotros caracteres de marcada gravedad. El paro de las faenas de Fábrica Liebig y el fracaso de las cosechas son circunstancias que han gravitado notablemente en esta zona para hacer de la desocupación un problema agudo e inquietante. Hasta este momento, fuera de la labor conocida de nuestra municipalidad para combatir ese mal y sus graves efectos con medidas de innegable beneficio para la clase obrera, ${ }^{20}$ nada se ha hecho en otros órdenes para coadyuvar a esa obra de alta finalidad social." 21

\footnotetext{
18Periódico El Debate, Gualeguay, 05/03/1932.

${ }_{19}$ Periódico Los Principios, C. del Uruguay, 15/01/1940.

${ }^{20} \mathrm{La}$ Municipalidad de Colón había comenzado un plan asistencialista que comprendía desde los servicios fúnebres gratuitos y la atención odontológica hasta la entrega de 10 mil pesos para generar empleo en el mejoramiento de los caminos y el dispendio de víveres a los más necesitados. Ver: $E l$ Entre Ríos, 17/08/1940, El Entre Ríos, 07/09/1940 y El Entre Ríos, 12/09/1940.

${ }^{21}$ El Entre Rios, 24/09/1940.
} 


\section{Comités pro-desocupados: intervención estatal, contención social y politica. Entre Rios, 1932-1943}

En este caso, defendía a la municipalidad, manejada por los conservadores, contra la provincia dirigida por los radicales, pero no existía discusión acerca de la necesidad de intervención del estado. El arco político burgués coincidia en el rol que debía asumir el estado.

\section{5- "Comités Pro-desocupados"}

Toda política necesita de su organización específica para ejecutarse. Para luchar contra la desocupación el gobierno nacional propuso la creación de un Registro Nacional de Colocaciones y la Junta Nacional para Combatir la Desocupación (JNCP), organizaciones que funcionaron con dependencias en las provincias ${ }^{22}$. Pero en Entre Ríos se destacó la aparición de los Comités de Desocupados o Prodesocupados.

El gobierno de la provincia tomó dimensión del fenómeno de la desocupación y la necesidad de la intervención por los resultados del primer censo nacional de desocupados en 1932. La siguiente fuente muestra la preocupación de buena parte de la dirigencia política con respecto a la desocupación y cómo el Estado provincial trató de concentrar la iniciativa para generar trabajo:

"Con el propósito de concretar la forma de combatir la desocupación aumentando las posibilidad de trabajo, el Poder Ejecutivo de la Provincia, ha dispuesto invitar a los legisladores de todos los sectores politicos, una reunión que tendrá lugar en la corriente semana. En esa reunión, el gobernador convendrá la forma de redactar un proyecto de ley, que consiga al parecer de toda la representación de la Cámara para resolver la desocupación. Se estudia también un plan de trabajo y facilitando tarea, el gobernador ofrecerá detalle de las obras cuya realización es más urgente y las cuales han sido reclamadas por vecindarios, entidades o han sido motivo de gestiones de legisladores..."23

Durante los meses siguientes, las ayudas quedaron en manos de las municipalidades, vecinos, y políticos particulares. Por ejemplo, en Concepción del Uruguay, los concejales presentaron un proyecto de constitución de ollas populares “...contemplando la precaria circunstancia económica y de evidente escases por que atraviesa el elemento jornalero y la clase más necesitada de la ciudad como consecuencia de la falta de trabajo." 24

Pero en enero de 1933, con la pérdida de la cosecha y el consiguiente aumento de la desocupación, se convocó una reunión de los Jefes de Policías que fue presidida por el Ministro de Gobierno. En la reunión se les planteó a los funcionarios el cuidado

${ }^{22}$ El Censor, Gualeguaychú, 12/05/1931. Para un resumen histórico de la Junta Nacional para Combatir la Desocupación y los debates consultar: Girbal-Blacha, 2003.

${ }^{23}$ El Entre Ríos, 12/07/1932.

${ }^{24}$ La Juventud, 17/09/1932. 
del orden y la necesidad de crear los Comités de desocupados como prioridad. Las órdenes eran las siguientes:

"1 $1^{\circ}$-Medidas para atenuar el problema de la desocupación. Se dispuso encomendar a los señores jefes de Policía la gestión de promover en cada departamento, en la forma que pueda resultar más eficaz y con la cooperación de las autoridades municipales en las ciudades y villas y con la de los vecinos, en los distritos de campaña, la organización de la ayuda a los desocupados, en lo posible mediante la creación de trabajos públicos locales o vecinales. Se recomendó requerir a este mismo efecto el concurso de las comisiones centrales de Puentes y Caminos como también en general, el de las instituciones vinculadas a las industrias, ganaderos, comerciantes.-

$2^{\circ}$-Aplicación de las leyes referentes al trabajo. Se recomendó a los jefes seguir las instrucciones preparadas por el departamento del Trabajo para la aplicación, control y vigilancia de las leyes 11544 (sobre jornada legal de trabajo) 11338 (sobre prohibición del trabajo nocturno en las panaderias) 2070 y 2937 (descanso dominical y hebdomadario) y 11278 (sobre el pago en dinero efectivo en moneda nacional). ${ }^{25}$

El hecho que los comisarios fueran las autoridades encargadas de encabezar y poner en funcionamiento las comisiones muestra hasta qué punto estas medidas eran asociadas al control social. Pero también el interés de las autoridades provinciales de dar poder a los comisarios, por entonces un cargo político designado por el gobernador, para generar el vínculo entre los desocupados y los administradores del estado provincial. (Leyes y Sartelli, 2019), concentrando en los comisarios las relaciones con la clase obrera, ya sea ocupada a través del departamento de trabajo como de los desocupados por la vía de las comisiones prodesocupados.

A partir de aquella orden de 1933 surgieron en los diferentes departamentos, pueblos y ciudades, las comisiones de trabajo. En Gualeguay, la constitución de la Comisión se dio pocos días después de la reunión de los jefes de Policía. Para su creación el comisario local invitó al Intendente de la ciudad, al presidente de la comisión de Puentes y caminos, el presidente de la Sociedad Rural y al presidente de la Comisión de Intereses Departamentales ${ }^{26}$. La nota que se dirigió a los futuros miembros recalcaba la necesidad de participar:

"La Comisión central espera de su reconocido patriotismo y buena voluntad, que asuma esta tarea, que reconocemos improba pero al mismo tiempo necesaria para la defensa, no solamente de las millares de familias que se encuentran en la

${ }^{25}$ El Censor, 28/01/1933.

26El Debate, 07/02/1933. Destacando el carácter predominantemente burgués de las comisiones, la de Paraná se reunía en el salón del Centro Comercial de la ciudad. Ver: Periódico El Tiempo, Paraná, $14 / 06 / 1933$. 
indigencia, sino también de los intereses generales de los vecindarios cuya integridad podría llegar a peligrar por imperio de la misma necesidad, que, como es fácil presumir, puede afectar las buenas costumbres y atacar los derechos a la propiedad privada, cosa que todos tenemos el deber de evitar.

Esta observación no es una alarma infundada puesto que cada día se va apreciando más el crecimiento de esta tendencia, pudiéndose contemplar en muchas partes, el espectáculo desagradable de personas que, no consiguiendo trabajo, se deciden, apremiadas por la pobreza, hacer uso de procedimientos poco edificantes como ilícitos."

Después de esta fundamentación basada en los intereses de la propiedad privada y el orden social, la nota hacía referencia a que la comisión consideraba a personas reconocidas por su actividad y eficiencia como garantía de éxito. La reglamentación de la comisión de desocupados de Gualeguay y sus sub-comisiones sirven de modelo de cómo se organizaban: $1^{\circ}$-Gestionar en el vecindario las donaciones, en especial alimentos, $2^{\circ}$-Hacer un censo de desocupados, $3^{\circ}$-Realizar obras de beneficio general, en particular caminos, desagües, terraplenes, destrucción de abrojos, $4^{\circ}$-Retribuir a los desocupados con las donaciones, $5^{\circ}$-No se realizarán más trabajos que los que sus recursos permitieran, $6^{\circ}$-Las sub-comisiones podían recibir donaciones en efectivo que se debia rendir a la Comisión Central y se utilizaría para pagar salarios. $7^{\circ}$-Los jornales serían fijados en $\$ 1,20$ y $\$ 1,50^{27}$ ya sea en efectivo o en especie. $8^{\circ}$-La comisión deberá procurar el alojamiento de los desocupados $^{28}$. Este modelo, con algunas variantes, fue el que se aplicó en la mayor parte de la provincia.

La mayor dificultad de las comisiones era el financiamiento. En algunos casos recibieron dinero de los municipios, aunque predominó la donación y la compra de bonos para contribuir. Esta financiación tan informal generó problemas. En junio de 1933, se informaba que la Comisión Pro-Desocupados de Paraná había hecho circular un pedido de donación para contribuir a la tarea. Recordaba que existían cuatro mil hogares en aquella ciudad, y que todo aporte, por pequeño que fuera, sería importante. En octubre los periodistas de La Acción de Paraná se quejaron: "Pensamos que quienes han ofrecido sus contribuciones pensaron cumplir este compromiso, y es preciso que así ocurra, que la comisión cuenta con estas en sus cálculos para llevar adelante el fin que persigue." 29 Esta comisión daba trabajo a 100 obreros que rotaban de semana en semana, para dar ocupación a otros trabajadores en igual número. Estos obreros habian construido escaleras en la zona del Puerto Nuevo, desviado un arroyo que amenazaba el cementerio local, pintado el

\footnotetext{
${ }^{27}$ Como referencia, el salario de los obreros estibadores de Diamante era de $\$ 5$. En 1941 , los obreros contratados por la Comisión Pro-desocupados de Gualeguaychú se quejaron por sus salarios de $\$ 1.50$. ver: Semanario BCGT, órgano de la Confederación General del Trabajo, Buenos Aires, 25/12/1933, p.2. El Censor, 16/09/1941.

${ }_{28}$ El Debate, 18/02/1933.

299eriódico La Acción, Paraná, 27/06/1933 y 28/10/1933.
}

\section{anuario.}


$\overline{\text { hospital de la ciudad y mejorado el Parque Urquiza }{ }^{30} \text {. La comisión llegó a conseguir }}$ que se done la recaudación de los cines, un día a la semana, para ser financiada ${ }^{31}$. En Gualeguay, se quejaban que una vez finalizados los recursos, hubo que despedir a las dos cuadrillas que trabajaban en el enripiado de la ciudad. Recriminaba que en otras ciudades de la provincia los donantes eran muchos, e incluso los bancos aportaban, “...mientras en esta ciudad, ni el Jockey Club, ni el Club Social o la Sociedad Rural lo estaban haciendo". Esta comisión llegó hacer una rifa para conseguir fondos ${ }^{32}$. Incluso en 1940, cuando los desembolsos oficiales eran la principal fuente de recursos, el semanario Crónica de Basavilbaso decía: "Los altos fines humanitarios de esta obra deben ser apoyados por todos y por ello, se solicita de todos los vecinos se sirvan hacernos llegar su adhesión pecuniaria en forma de cuotas mensuales fijas, por el término de dos a tres meses, es decir hasta que se normalice esta irregular situación." 33

Pero la situación de los pagos no era mejor. Eran repetidos los reclamos de las autoridades, medios de prensa y lógicamente, de los obreros, por los atrasos de los salarios. Por ejemplo, en 1933 se informaba que obreros encargados de los caminos en la estación Irazusta, departamento de Gualeguaychú, reclamaban por dos meses sin pago:

"No es la primera vez que esto ocurre, afirman y reina malestar entre los obreros que amenazan con un paro. Llaman a la policía a cumplir con su deber y levantar las actas de reglamento para enviarlas y solicitar la intervención de la Oficina Nacional de Trabajo. No es cosa que después, si ocurren hechos desagradables se acuse a los obreros de comunismo, cuando reclaman con energía lo que legitimamente les corresponde." 34

En Nogoyá, el Periódico El Parque se quejaba de las largas colas que debían soportar, incluso por la noche, los obreros desocupados para cobrar su trabajo: "Aún estaban ahí gran número de obreros. Pues señor, ahora no se quejarán de que no tienen algo en que ocuparse. Por lo menos, tienen trabajo para que trabajen y luego...tienen trabajo para cobrar", ironizaba35.

Sin embargo, mientras los recursos existian, la acción de las Comisiones era destacada. En Nogoyá, la comisión dirigida por el Comisario realizó tareas de mejoramiento de los caminos y desagües en cinco localidades. Se ocupó en Lucas González a 180 obreros, en Chiqueros a 45 obreros, en Veinte de Septiembre a 25

\footnotetext{
30Periódico El Tiempo, Paraná,18/05/1933.

31Vespertino El Diario, Paraná, 04/08/1933.

32El Debate, 06/09/1933. El Debate, 30/06/1933.

${ }^{33}$ Semanario Crónica, Basavilbaso, 31/08/1940.

${ }^{34}$ El Debate, $11 / 08 / 1933$.

35Periódico El Parque, Nogoyá, 21/10/1940.
} 


\section{Comités pro-desocupados: intervención estatal, contención social y politica. Entre Rios, 1932-1943}

obreros, en Crucecitas a 30 obreros y en Estación Hernández y Laurencena. Decía El Diario de Paraná al respecto de los trabajos en Hernández:

"La carne fue donada por fuertes hacendados y la galleta se adquirió con el producto de donaciones en efectivo. La preocupación del señor jefe de la policía para que el problema de la desocupación fuera combatido en esa forma, ha causado buena impresión en los vecindarios por cuanto merced de esa dedicación ha podido solucionarse en parte la situación desesperante de numerosas familias afectadas por la real escasez de trabajo." 36

La Comisión constituida en Villaguay, en el lapso de poco menos de un mes había dado trabajo a 189 obreros en turnos rotativos. Por su parte, había gestionado que el Tiro Federal de dicha ciudad ocupara 46 obreros, mientras la comisión de puentes y caminos a otros 50 desocupados. La Comisión se jactó de dar ocupación a 285 obreros sobre los 353 desocupados inscriptos ${ }^{37}$. En Rosario del Tala, la comisión donó 500 kilos de carne, 250 galletas y 650 kilos de maíz pisado y harina de maíz entre 1.400 inscriptos para recibir comida ${ }^{38}$.

El camino de las comisiones no estuvo sembrado de flores, sino más bien, de los escollos de un Estado quebrado dentro de un sistema en crisis. La falta de recursos dejó a cada una de las comisiones al libre albedrío y las posibilidades de sostenimiento por parte de las comunidades directamente afectadas. Incluso, el gobernador elevó pedidos de fondos a la Junta Nacional para Combatir la Desocupación, solicitudes que fueron rechazadas ${ }^{39}$. Hacía 1939 se aprobó la ley 3.234, en la cual se autorizaban partidas de dinero para las Comisiones por un total de 100 mil pesos moneda nacional (Reula, 1971: 98), lo que de facto implicaba su reorganización. A partir de septiembre de ese año se reorganizan las Comisiones de Gualeguay, Tala, Nogoyá, Victoria, Gualeguaychú, Diamante y Colón ${ }^{40}$. En todas las localidades las comisiones estaban en manos de los jefes de policía con la participación de los intendentes municipales, senadores o diputados, según dispusieran en el territorio ${ }^{41}$.

En 1940, el Gobernador Mihura encargó un nuevo censo de desocupados a los jefes de Policía. Los resultados eran catastróficos. Entre la última quincena de julio y la primera de agosto de 1940, había 10.336 obreros desocupados, casi el doble de los registrados el año anterior (Mihura, 1941: 8). Por su parte, la estadística nacional elaborada en 1940, afirmaba que la provincia de Entre Ríos poseía desocupación en toda su extensión territorial. El número era levemente menor (redondeada en diez mil desocupados) e indicó que eran los jornaleros rurales los más afectados. Para revertir la situación se informó las medidas de reorganización, capitalizando las

\footnotetext{
${ }^{36}$ El Diario, Paraná, 15/07/1933.

${ }^{37}$ El Diario, 16/09/1933.

${ }^{38}$ El Debate, 30/03/1933.

39Junta Nacional para Combatir la Desocupación, 1937: 192.

40El Diario, 26/09/1939.El Entre Ríos, 25/10/1939.

${ }^{41}$ La Juventud, 23/09/1939.
}

\section{anuario.}


Comisiones de desocupados y un plan provincial de obras públicas (Ministerio del Interior, 1940: 12; 38).

En 1941 se mantenian en funcionamiento 113 comités pro-desocupados en Entre Ríos, que recibieron durante todo el periodo la suma de 150.900 mil pesos M/N. Decía Mihura, frente a las Cámaras Legislativas, en la apertura de sesiones de 1942:

\begin{abstract}
"En determinados casos fue necesario prescindir del requisito de la contribución vecinal, por la imposibilidad absoluta de obtenerla en lugares donde la depresión económica acusaba caracteres más agudos y generales (...) El recrudecimiento del problema de la desocupación, que habitualmente se agrava durante el invierno, impondrá en breve la necesidad de restablecer las actividades de las comisiones, arbitrando al efecto nuevos recursos, para cuya inversión recabaré oportunamente a V. H. la autorización correspondiente." (Mihura, 1942: 19)
\end{abstract}

Dicho de modo sintético, a más desocupación, más intervención estatal. En 1942, se aprobó otro desembolso de un millón de pesos ${ }^{42}$. Casualmente, este desembolso de dinero coincidió con un período pre-electoral (las elecciones provinciales de marzo de 1943). Las denuncias del uso proselitista, como ya se señaló, no se hicieron esperar ${ }^{43}$.

\title{
6- Comisiones pro-desocupados y politica
}

En una provincia quebrada económicamente, las comisiones pro-desocupados facilitaron a los políticos burgueses, sean radicales o conservadores, recursos para desarrollar sus actividades. Es decir, el manejo de los recursos y su administración habilitaron nuevos vínculos entre los sectores de la clase dominante y la clase obrera desocupada. Permitía a quién administrara la Comisión pro-desocupados tejer una relación de dependencia entre los desocupados y los encargados de ofrecer empleo. Este lazo, llamémosle clientelar, reconfiguró las relaciones entre los partidos y el proletariado, y será una de las prácticas políticas más persistentes en la vida política argentina ${ }^{44}$. Pero justamente, por su utilidad práctica para la dominación de clase, es que hizo de las Comisiones pro-desocupados fueran espacios de disputa, de tensión y, hay que decirlo, repetidos desfalcos.

${ }^{42}$ La Juventud, 22/08/1942.

${ }^{43}$ El Censor, 19/04/1943.

${ }^{44}$ La relación entre el otorgamiento de empleo de los sectores burgueses a la clase trabajadora no era una novedad. Fácilmente se puede reconocer como un antecedente la presidencia de Yrigoyen, también era una práctica extendida entre los adherentes a los diferentes partidos en el interior. Una versión moderna y aggiornada del vínculo paternalista de los caudillos con los trabajadores. Una relación vertical entre quienes quienes poseen capital y quienes deben vender fuerza de trabajo para vivir, pero tendientes a la creación de un vínculo político-electoral. Ver: Rock, 2001: 124.

\section{anuario.}




\title{
Comités pro-desocupados: intervención estatal, contención social y politica. Entre Rios, 1932-1943
}

En junio de 1933, el Diario del Pueblo de Colón ironizaba sobre la disputa por los recursos obtenidos y el escándalo que se produjo entre el Intendente y los miembros de la Comisión:

\begin{abstract}
"Después de laboriosa gestión de meses en la que se invirtieron viáticos y gran cantidad de combustible para el auto policial, el señor jede de la repartición policial logró reunir algunas vacas que en realidad resultan de oro, si nos atenemos al gasto que se originó con el motivo anotado ¿iSería interesante conocer el monto? Finalizadas las gestiones, el mismo funcionario designa, por su cuenta, una comisión de calificados vecinos, pero con exclusión de otros no menos calificados y conocedores del ambiente popular, lo que los habilita para una equitativa distribución de viveres a los que realmente necesitan y no a los 'pulpos' que en esta circunstancia forman legión." -Continuaba: "La mayoría de la comisión parece que se ha opuesto a que sea, como corresponde, la comuna quién administre los fondos y proceda a la distribución de víveres. Tenemos entendido que el señor Intendente, ahí presente, formuló moción en ese sentido, pero primó la de los que sostienen que debe ser la policía y la Comisión quién entregará los recursos de referencia. Planteada la divergencia en tal forma, el Intendente que había ofrecido donar los sueldos que percibe como tal por junio, julio, agosto, contribuyendo además la comuna con 100\$ mensuales, resolvió no prestar su valiosa cooperación, pero en cambio, sabemos que proyecta hacerlo por separado, dando trabajo a gran números de obreros si la Comisión 'Pro-Desocupados' no vuelve sobre sus pasos y toma el buen camino a seguir. Tiene la misma un presidente sensato y esperamos que en homenaje al proletariado local el entredicho -si asi puede llamarse- tendrá satisfactoria solución"45
\end{abstract}

Aquí vemos como la falta de un plan sistemático y, sobre todo, la falta de recursos, permitieron a los políticos burgueses utilizar la situación para sus fines. Algo similar pasó en Gualeguay donde se denunció que la comisión había comenzado sus actividades entre aplausos para después no volver a reunirse. Pregonaba: "Las clases pudientes no pueden mostrarse reacias a la contribución en pro del trabajo para los desocupados; lo impone asî un deber de solidaridad social y humanitarismo..."46. Esta comisión en particular fue investigada por las autoridades intervinientes en 1943 luego del golpe de Estado de ese año, y señalaron que el dinero que disponían había sido utilizado para pagar al chofer de un camión de propaganda política, en otro caso aparecía numeroso personal municipal que firmaba como desocupado para cobrar doble sueldo. Estos hechos contrastaban con casos de desocupados reales a los que les adeudaban sueldos ${ }^{47}$. No fueron los únicos casos investigados por los militares. En Nogoyá, el mal uso del dinero público terminó con el encarcelamiento del ex comisario, se denunciaba una situación parecida en localidades como Nueva Escocia, La Paz, Puerto Yeruá y Villa

\footnotetext{
${ }^{45}$ Diario del Pueblo, Colón, 08/06/1933.

${ }^{46} \mathrm{El}$ Debate, 25/08/1933.

${ }^{47} \mathrm{El}$ Censor, 28/02/1944.
} 
Urquiza ${ }^{48}$. Estos casos eran denunciados en el momento que sucedian, como lo hizo Tribuna Socialista de Basavilbaso:

"Hace ya varios meses que dista desde la última campaña politica, muchos ciudadanos ilusos, soñaban con la prebenda consabida por sus sacrificios partidarios: los demócratas nacionales prometian puestos en las reparticiones nacionales, Banco de la Nación, Ministerio de Obras Públicas, etc.; los radicales antipersonalistas lo hacian a su vez dentro de la provincia..." 49

El uso de las comisiones para fines electorales fue una denuncia sostenida, y no solo contra los políticos que participaban, sino también contra los comisarios que las presidian, como fueron los casos de Gualeguaychú y Victoria en donde los desocupados debian primero afiliarse a la UCR para acceder a los trabajos ${ }^{50}$.

Con la última derrota de los conservadores contra los radicales, en las elecciones de marzo de 1943, los perdedores señalaban que el millón de pesos aprobado para combatir la desocupación se había utilizado para proselitismo:

"El trabajo debia otorgarse exclusivamente a los desocupados inscriptos en los registros oficialistas, debiendo contribuir todos ellos con la tercera parte de sus jornales para la 'caja del partido' (...) llegó el momento de la elección y los desocupados debian permanecer en sus campamentos, bajo riguroso contralor policiaco, entregando sus libretas civicas debiendo votar exclusivamente aquellos que no ofrecieran dudas y siempre bajo la implacable presión policial (...) ¿Es o no el hecho que comentamos una despiadada mofa de las clases humildes?..."51

Efectivamente, nadie dudaba que se hubiera tejido un andamiaje contractual entre los desocupados y los políticos que manejaban las Comisiones pro-desocupados. Lo que parecía una politica de beneficios mutuos, en realidad ocultaba la necesidad de los obreros de conseguir trabajo, más allá de las lealtades políticas encorsetadas por la necesidad.

\section{Conclusión}

Podriamos decir que los últimos años de la década del veinte y los primeros años de la década del treinta marcaron un cambio profundo en la estructura social de la provincia de Entre Ríos. Por aquellos años se vivió una conmoción en su aparato productivo que generó el crecimiento de la desocupación de un modo nunca visto.

${ }^{48}$ El Censor, 05/01/1945. El Diario, 01/01/1944. El Diario, 14/01/1944.

${ }^{49}$ Periódico Tribuna Socialista, Basavilbaso, Órgano del Centro Socialista “José Ingeniero", Mayo de 1934.

50Periódico El Argentino, Gualeguaychú, 11/11/1942. Periódico Crónica, Diamante, 16/02/1943, p.1. El Entre Rios, 01/04/1943.

${ }^{51}$ El Entre Ríos, 01/04/1943. 
Ya no sería la desocupación temporaria, flotante, sino un nuevo tipo de desocupación permanente, y con ella, la conformación de una masa de desocupados que ascendería, en promedio, a diez mil a veinte mil personas. Número que puede ser mayor si consideramos los miles que abandonaron la provincia.

Esta masa de obreros sobrantes para la producción capitalista pronto fue vista por los sectores burgueses como un peligro para sus propiedades y el orden social. Asustados por la posibilidad del encuentro entre los desocupados y el comunismo, temian que aquellos que habian perdido el trabajo les hicieran perder todo. Entonces fue naciendo un anticuerpo de clase, la intervención estatal como medida de contención social. Se llamó desde diferentes espectros del arco político burgués (y diversas regiones de la provincia) al estado para que asuma la tarea de dar ocupación a los desempleados.

Así fue que en 1932, luego de los resultados catastróficos del primer censo nacional de desocupados, se constituyeron Comisiones pro-desocupados en la provincia con el objetivo de generar empleo público y ocupar a los desempleados. Las comisiones, si bien carentes de financiación centralizada en un principio, tomaron en su gestión varias tareas de obras públicas menores, arreglos de caminos, mejoramiento de los edificios públicos, etc. Pero hacia fines de la década del treinta, cuando el fenómeno de la desocupación se mantenía al orden del día, el gobierno provincial decidió financiar las comisiones con dinero público.

Los contemporáneos reconocieron la utilidad de estas comisiones en su tarea explícita, dar ocupación, pero también entendieron que las comisiones prodesocupados podian cumplir otros fines. En este sentido, el uso de las comisiones para fines políticos, que buscaran vincular a los trabajadores sin trabajo con los políticos burgueses, estaba implícito en la propia estructura que ordenaba a las comisiones, presididas por comisarios -por entonces un cargo político-, diputados y senadores. En todos los casos, las comisiones se volvieron espacios de disputa para la administración de los recursos necesarios para establecer un vínculo clientelar con el proletariado desocupado.

Durante la década de funcionamiento de las comisiones de desocupados se dio empleo a miles de trabajadores, pero más profundo fue el cambio que se vivió en el estado y en la opinión pública sobre la obligación de dar ocupación a los desempleados. A final de cuentas, este artículo da muestras del origen histórico del vínculo empleo-estado-partidos políticos. 


\section{Bibliografia}

Arnaiz, M. del C. (1991). "Aires libertarios: la Federación Obrera Comarcal Entrerriana. 1920-1940” en Anuario IEHS, n 6, Tandil.

Balsa, J. y Lázzaro, S. (2012): Agro y política: El modelo agrario en cuestión, 1930-1943, Buenos Aires, Ed. Ciccus, Tomo I.

Barsky, O. y Gelman, J. (2005). Historia del agro argentino, Buenos Aires, Mondadori.

Béjar, M. D. (2005). El régimen fraudulento. La política en la provincia de Buenos Aires, 1930-1943, Buenos Aires, Siglo XXI Editores.

Benclowicz, J. (2016). "Un movimiento de desocupados para la revolución El Partido Comunista y la organización de los trabajadores desocupados hacia la década de 1930 en Argentina". En Revista de Historia Americana y Argentina, Vol. 51, No 2, Mendoza, Universidad Nacional de Cuyo.

Biaziso, R. (2015). Economía de Entre Ríos en el periodo de intervencionismo conservador, 1930-1945, Paraná, Universidad Nacional de Entre Ríos, UNER.

Gaudio, R. y Pilone J. (1983). "El desarrollo de la negociación colectiva durante la etapa de modernización industrial en la Argentina, 1935-1943". En Desarrollo Económico, Vol. 23, Nº 90.

Gaudio, R. y Pilone, J. (1984). "Estado y relaciones laborales en el período previo al surgimiento del peronismo, 1935-1943”. En Desarrollo Económico, Vol. 24, No 94.

Germani, G. (1961). Política y sociedad en una época de transición, Buenos Aires, Paidos.

Girbal-Blacha, N. (2003). "La Junta Nacional para Combatir la Desocupación. Tradición y modernización socioeconómica en la Argentina de los años treinta" en Estudios del Trabajo, Buenos Aires, $n^{\circ} 25$, enero-junio.

Iñigo Carrera, N. (2016). La Otra estrategia. La voluntad revolucionaria (19301935), Buenos Aires, Imago Mundi.

Kabat, M. (2009). "La sobrepoblación relativa. El aspecto menos conocido de la concepción marxista de la clase obrera”. En Anuario CEICS 2009, Año 3, Número 3, Buenos Aires. 
Kabat, M. y Leyes, R. (2018). Ciclos de luchas sindicales en la provincia de Entre Ríos, Argentina, 1930-1943, Estudios del ISHiR, Nº 22.

Korzeniewicz, R. (1993). "Las vísperas del peronismo. Los conflictos laborales entre 1930 y 1943”. En Desarrollo Económico, Vol. 33, N 131, Oct.-Dic.

Leyes, R. (2016). "Caravanas de hombres marchaban: El éxodo obrero en Entre Ríos. 1925-1945” en Folia Histórica del Nordeste, N²7, Resistencia, Chaco, Diciembre.

Leyes, R. (2018)."Detrás de las crisis: Inversiones de capital, mecanización y desocupación en Entre Ríos, 1928-1946". En Pampa. Revista Interuniversitaria de Estudios Territoriales. $\mathrm{N}^{\circ} 17$, Santa Fe-Montevideo.

Leyes, R. (En prensa). Sindicatos de izquierdas, obreros radicales. La alianza Radical-movimiento gremial en Entre Ríos: 1921-1943. En Videla, Oscar (Comp.). Historias locales, conflictividades múltiples (Santa Fe y Entre Ríos durante el siglo XX).

Leyes, R. y Sartelli, E. (2019). "Departamento Provincial del Trabajo de Entre Ríos. Intervencionismo laboral y reformismo obrero, 1930-1943”. En Historia Regional, N 40 , Villa Constitución, Segundo Semestre.

Lobato, M. y Suriano, J. (2013). La sociedad del Trabajo. Las instituciones laborales en la Argentina (1900-1955), Buenos Aires, Edhasa.

Mastrángelo, M. (2011). Rojos en la Córdoba obrera 1930-1943, Buenos Aires, Imago Mundi, 2011.

Mora y Araujo M. y Llorente, I. (1980). El voto Peronista. Ensayos de sociología electoral argentina, Buenos Aires, Ed. Sudamericana.

Murmis, M. y Portantiero, J. C. (2006). Estudios sobre los orígenes del peronismo, Buenos Aires, Siglo XXI Editores.

Nemirovsky, L. (1933). Estructura económica y orientación política de la Agricultura en la República Argentina, Buenos Aires, Casa editora de Jesús Menéndez.

Ortiz, R. (1964). Historia económica de la Argentina: 1850-1930, Buenos Aires, Ediciones Pampa y Cielo.

Panettieri, J. (1996). "Paro forzoso y colocación obrera en Argentina en el marco de la crisis mundial (1929-1934)", Cuadernos del CISH, 1. Recuperado de http://www.memoria.fahce.unlp.edu.ar/art_revistas/pr.2489/pr.2489.pdf 
Panettieri, J. (1997). "Crisis económica; perturbaciones en el mundo del trabajo y movimientos de población. 1937-1943”, Cuadernos del CISH, 2 (2-3). Recuperado de http://sedici.unlp.edu.ar/bitstream/handle/10915/13617/Documento_comp leto.pdf?sequence $=1 \&$ is Allowed $=y$

Reula, F. (1971). Historia de Entre Ríos, Santa Fe, Ed. Castellví, Tomo III.

Rock, D. (2001). El radicalismo argentino, 1890-1930, Buenos Aires, Amorrortu.

Schvarzer, J. (2000). La industria que supimos conseguir: Una Historia politico social de la Industria Argentina, Buenos Aires, Ed. Cooperativas.

Sidicaro, R. (1995). "Los conflictos entre el Estado y los sectores socioeconómicos predominantes en la crisis del régimen conservador (19301943)"en Ansaldi, Waldo; Pucciarelli, Alfredo \& Villarruel, José (Editores): Representaciones inconclusas. Las clases, los actores y los discursos de la memoria, 1912-1946, Buenos Aires, Editorial Biblos.

Tcach, C. (1991). Sabbatinismo y peronismo:Partidos políticos en Córdoba, Buenos Aires,Sudamericana, 1991.

Ulivarri, M. (2009). "Trabajadores, Estado y política durante las gobernaciones radicales en Tucumán 1935-1943", Anuario del Centro de Estudios Históricos "Prof. Carlos S. Segreti", Vol. 9, N 19, 2009.

Documentos y fuentes:

Entre Ríos (1940). Boletín del Departamento del Trabajo, Paraná, Septiembre 1940.

Junta Nacional para Combatir la Desocupación (1937). Memoria elevada al Ministerio del Interior, 1937, Buenos Aires.

Mihura, E. (1940). Mensaje del Gobernador de la provincia de Entre Ríos Dr. Enrique Mihura al iniciarse el $81^{\circ}$ periodo ordinario de sesiones de la Honorable Legislatura. Julio 1940, Paraná, Imprenta de la Provincia.

Mihura, E. (1941). Mensaje del Gobernador de la provincia de Entre Ríos Dr. Enrique Mihura al iniciarse el $82^{\circ}$ periodo ordinario de sesiones de la Honorable Legislatura. Julio 1941, Paraná, Imprenta de la Provincia. 
Mihura, E. (1942). Mensaje del Gobernador de la provincia de Entre Ríos Dr. Enrique Mihura al iniciarse el $83^{\circ}$ periodo ordinario de sesiones de la Honorable Legislatura. Julio 1942, Paraná, Imprenta de la Provincia.

Ministerio de Agricultura (1940). Censo Nacional y Agropecuario, 1937, Buenos Aires, Guillermo Kraft.

Ministerio del Interior. Departamento Nacional del Trabajo (1940). La desocupación en la Argentina: 1940, Buenos Aires, Departamento Nacional de Trabajo.

Ministerio del Interior. Departamento Nacional del Trabajo, Figuerola, J. (1933). La desocupación en la Argentina: 1932, Buenos Aires, Departamento Nacional de Trabajo.

República Argentina (1909). Censo Agropecuario Nacional, la ganadería y la agricultura en 1908: La Ganadería, Buenos Aires, Talleres de Publicaciones de la Oficina Meteorológica.

República Argentina (1916). Tercer Censo Nacional, Tomo I, Antecedentes y comentarios, Buenos Aires, Talleres Gráficos L. J. Rosso y Cía.

República Argentina (1917). Tercer Censo Nacional, Tomo IV, Población, Buenos Aires, Talleres Gráficos L. J. Rosso y Cía.

República Argentina (1946). Dirección de Estadística Social: Investigaciones Sociales, 1943-1945, Buenos Aires.

República Argentina (1949). Ministerio de Asuntos técnicos, IV Censo General de la Nación, Censo Poblacional, Tomo I, Dirección del Servicio Estadístico, Buenos Aires.

República Argentina (1952). Ministerio de Asuntos técnicos del Estado, Dir. Gen. Del Serv. Est. Nacional, IV Censo General de la Nación: Censo Agropecuario de 1947, Buenos Aires, Dirección Nacional del Servicio Estadístico.

Situación económica de la Provincia de Entre Ríos. Informe sobre la gira realizada por los Srs. Directores don Pedro Benegas y don Pedro Etchegaray y gerente de Sucursales don Manuel Gómez, los días 19, 20 y 21 de enero de 1933, en Archivo General de la Nación. Sala VII. Fondo Agustín P. Justo. Caja $\mathrm{N}^{\circ} 42$, documento $\mathrm{N}^{\circ} 25$.

\section{$\underline{\text { Periódicos y diarios }}$}

Periódico Antorcha, Gualeguaychú, Órgano Centro de Estudiantes de Filosofia. 
Periódico Crónica, Diamante.

Periódico Diario del Pueblo, Colón.

Periódico El Argentino, Gualeguaychú.

Periódico El Censor, Gualeguaychú.

Periódico El Debate, Gualeguay.

Periódico El Entre Ríos.

Periódico El Litoral, Concordia.

Periódico El Parque, Nogoyá.

Periódico El Pueblo, Villaguay.

Periódico El Tiempo, Paraná.

Periódico La Acción, Paraná.

Periódico La Juventud, Concepción del Uruguay

Periódico La Provincia, Paraná.

Periódico Los Principios, Concepción del Uruguay.

Periódico Tribuna Socialista, Basavilbaso, Órgano del Centro Socialista "José Ingeniero".

Semanario BCGT, Buenos Aires, órgano de la Confederación General del Trabajo

Semanario Crónica, Basavilbaso.

Vespertino El Diario, Paraná.

Recibido: 13 de febrero de 2020

Aceptado: 15 de marzo de 2020

Versión Final: 30 de abril de 2020 